\title{
Reflexão sobre os desafios da pós-graduação: novas perspectivas sociais, conhecimento e poder
}

\author{
Bernardete Angelina Gatti \\ Fundação Carlos Chagas e Pontifícia Universidade Católica de São Paulo, \\ Programa de Pós-Graduação em Psicologia da Educação
}

\section{Introdução}

O momento pelo qual passa o sistema de pós-graduação no Brasil, neste início dos anos 2000, é interessante e merecedor de atenções por parte de diferentes segmentos sociais. Observadores mais aguçados têm percebido que, diante dos desafios históricos a enfrentar, a pós-graduação não pode ser mais assunto apenas do círculo restrito das universidades, ou apenas do olhar de "pares" - o que cria uma perspectiva endógena, em geral pouco renovadora. Os vários desafios que hoje se colocam à pós-graduação dizem respeito a questões sociais mais amplas, que transcendem os muros do ensino superior. Não que as necessidades qualitativas deste ensino e da pesquisa não sejam grandes e muito importantes. Mas, novas questões vêm sendo trazidas no bojo da história social que viemos construindo nos últimos quarenta anos.

Diante do quadro sociocultural com que nos defrontamos hoje, e as perspectivas de humanidade que começamos a descortinar, o sistema de pós-graduação carece de análises quanto às suas finalidades e, portanto, quanto a qualidades relevantes a serem deles esperadas nos anos vindouros. Análises estas que sejam realizadas por diferentes fontes e com perspectivas mais críticas, no sentido construtor que tem a verdadeira crítica: aquela que é capaz de trazer novos fundamentos e dinâmica para a estrutura e o funcionamento desses cursos; aquela capaz de trazer visões diversificadas que possam criar embates e busca de consensos ampliados socialmente.

Não é possível mais desconsiderar, nas discussões sobre a pós-graduação, o fato de que o momento histórico hoje mostra diferenças visíveis em relação ao momento histórico em que os primeiros programas foram implementados e tiveram seus primeiros desenvolvimentos nas décadas de 1970 e inícios dos de anos 1980. Naquele momento os cursos de pós-graduação - mestrados e doutorados - foram criados, apoiados e sustentados em seu desenvolvimento sob um certo modelo e vocação não discutidos amplamente, mas gestados por setores da burocracia estatal em consenso com algumas lideranças acadêmicas, e, por isto mesmo, um modelo voltado ao desenvolvimentismo e à formação de quadros para a pesquisa e para as universidades, dentro de uma certa concepção sobre ciên- 
cia, sobre seu papel e os das tecnologias e sua produção/reprodução.

Mestrados e doutorados em nosso país originaram-se então, não do desenvolvimento da pesquisa científica nas universidades ou outras instituições, mas de uma política deliberada de organismos estatais, no final da década de 1960 e inícios de 1970. No ensino superior, à época, pouca pesquisa se desenvolvia, vez que sua vocação era dirigida sobretudo à formação de profissionais liberais. As universidades nasceram da agregação de cursos e pouquíssimas tinham a pesquisa como parte integrante do trabalho de seus docentes. A grande expansão havida no ensino superior, no início dos anos de 1970, trouxe também a improvisação de professores, sem formação especializada e em pesquisa, os quais vieram a atuar em instituições com instalações também improvisadas, que levavam ao ensino superior a idéia tradicional de que para esse ensino bastam as salas de aula e professores com algum bacharelado. Estamos falando de apenas vinte ou trinta anos atrás e os traços dessa situação ainda estão presentes em grande parcela dos cursos de nível superior. A precariedade de recursos, para este ensino, naquele período, é mostrada em vários estudos, ressaltandose, por exemplo, o estado miserável das bibliotecas, em especial a não disponibilidade de periódicos científicos. Nestas condições, também a pesquisa vai ser induzida através da política de criação e apoio aos cursos de mestrado e doutorado, que passam a ser estimulados e financiados em sua implementação em algumas universidades que apresentavam maior solidez institucional. Verbas substanciais de diferentes origens foram dirigidas a esse nível de formação como parte do esforço ligado ao "milagre brasileiro". Bolsas para mestrado e doutorado no exterior são concedidas num esforço dirigido à formação nesse nível, especialmente em áreas como as da economia, ciências básicas e tecnológicas. Estes estímulos à pós-graduação stricto sensu e à pesquisa dirigiram-se à formação de quadros e grupos de pesquisa de alto nível, sob a perspectiva do "capital humano". Esta ação "obedecia a uma decisão explícita, por parte do governo militar recémestabelecido, de disciplinar e orientar o ensino supe- rior no país, que culmina com a ampla reforma universitária implantada a partir de 1968. Seu escopo é a modernização do ensino superior nos quadros do projeto de desenvolvimento econômico adotado" (Durham, 1996, p.11) Visando superar a estrutura tradicional vigente no ensino superior, as mudanças, levadas a efeito na estrutura e currículos nas instituições atuantes nesse nível, e a introdução dos mestrados e doutorados buscavam a integração da pesquisa dentro dessas instituições. Esses esforços tiveram alguns desdobramentos positivos. Resultados importantes nos quadros institucionais e nos horizontes tanto da vida científica como nas áreas tecnológicas no país foram decorrentes dessa política. Mas, esses resultados, sem dúvida, ficaram vinculados a poucas instituições e regiões, se considerarmos a expansão demográfica do país, o volume do ensino superior e a demanda potencial de formação de professores para atuar neste nível de ensino, e as necessidades de desenvolvimento de variadas áreas científicas. A concentração do "conhecimento" em relativamente poucos grupos foi notória. Sobre esta questão, extremamente importante, voltaremos a falar adiante.

A integração da pesquisa como parte da vida universitária, como processo induzido, via mestrados e doutorados, acaba por criar uma vinculação excessiva entre a pesquisa e a pós-graduação na maioria das instituições, quando o desejável seria um espalhamento das atividades de investigação científica dentro de toda a vida acadêmica. $\mathrm{O}$ que se assistiu na maioria das instituições foi à concentração das atividades de pesquisa na pós-graduação, sendo aí o único espaço em que alguma pesquisa veio a ser realizada. Várias universidades, especialmente públicas e algumas comunitárias, caminharam lentamente para o desenvolvimento de grupos científicos que se interligam com os cursos de mestrado e doutorado, mas que adquiriram vida própria e têm um espaço institucional específico conectando-se com diferentes atividades acadêmicas. Porém, a grande maioria das instituições, especialmente as privadas, não integraram a pesquisa em seu cotidiano, trabalhando praticamente só com professoreshoristas. Também não se empenharam quanto ao aper- 
feiçoamento dos seus quadros, a não ser mais recentemente, por pressão de normatizações legais.

Desde sua origem, mestrados e doutorados foram destinados a uma elite. A seletividade para ingressar era altíssima; na ausência de parâmetros, pela inexistência desses cursos no país e o estímulo inicial aos mestrados especialmente, as dissertações de mestrado exigidas eram quase sempre equivalentes a teses de doutorado, se comparadas internacionalmente. Na verdade, adotaram-se em várias áreas, para o mestrado, padrões que em outros países encontravam-se nos doutorados. Além da seletividade inicial, a evasão também se mostrava alta. Hoje ainda, em círculos dominantes da vida científica no país, há um discurso, repetido, sobre a pós-graduação stricto sensu, que traduz a perspectiva de uma elite que identifica os mestrados como formadores de pesquisadores, como se este nível de ensino pudesse prover toda esta formação e somente esta formação. Concebem-se os cursos de mestrado e doutorado para uma elite pensante, para a formação dos pesquisadores por excelência e, por isso, sua expansão é tratada como devendo ser contida, e sua avaliação centralizada para melhor controle. Outras funções, inicialmente também propostas como parte das atribuições de mestrados e doutorados, foram minimizadas e deixadas de lado, por exemplo, a de formar professores para o ensino superior, o que é muito diferente de formar pesquisadores. Este é um dos desafios que vêm sendo colocados à pós-graduação e que se agudizará cada vez mais. Mesmo que os dois tipos de formação possam e até devam ser desenvolvidos simultaneamente, com a camisa de força dos prazos de conclusão para esses cursos, não é difícil pensar que é preciso fazer opções quanto à vocação dos programas de mestrado e doutorado, e repensar suas estruturas e currículos. Agregando-se, também, às duas finalidades já mencionadas, o objetivo de formar quadros para o trabalho em nível maior de sofisticação em relação às graduações - demanda clara dos profissionais e de vários setores comunitários - e outras funções que passam a ser esperadas desses cursos, associadas a aprofundamento e ampliação culturais, a questão da finalidade dos cursos e de seus objetivos, especialmente os de mestrado, começam a tomar contornos que extravasam o âmbito dos laboratórios de pesquisa e da carreira docente no ensino superior.

Assim, conforme analisa Guadilla (1997, p. 105106), diferentemente de alterações em níveis de educação superior realizadas em outros momentos deste século,

\section{[...] quando os atores responsáveis por elas foram agentes endógenos - estudantes algumas vezes, pesquisadores e diri- gentes das instituições outras vezes -, a agenda de transfor- mações na década de 90 está sendo construída, como se indicou antes, com novos agentes, alguns deles de fora da universidade. Isso tem sido interpretado de diferentes manei- ras. Uma delas se refere ao papel primordial do conhecimento nos novos sistemas produtivos, o que significa que hoje os agentes externos têm um interesse maior pelos sistemas de produção de conhecimento e de formação.(grifo nosso)}

Além disso, simultaneamente, e considerando a emergência de mudanças substanciais que caracterizam, segundo a autora, na passagem de uma etapa civilizatória a outra, um grande número de instituições de educação superior, com seus diversos níveis, encontra-se em condições de enclausuramento. Esta condição gera reações de paralisia e de defesa "pois, a perplexidade diante das mudanças, às vezes, é muito grande. Na vida dos acadêmicos, sobretudo, a passagem de uma etapa civilizatória a outra implica, em muitos casos, a desvalorização repentina de um capital cultural que se esteve acumulando durante toda vida profissional" (Idem, ibidem). Implica também, alterações de relações de poder, com uma dinamização diferente de estruturas já bem instituídas, com papéis assegurados.

Os atores desta transformação serão as pessoas que possuem sensibilidade ao social e que por isso se preocupam com a falta de eqüidade social e incorporam positivamente os avanços da nova etapa civilizatória.

\section{Papel social e estruturas da pós-graduação}

Em atmosfera de intenso debate quanto ao papel e às finalidades da pós-graduação e da qualidade de 
suas propostas acadêmicas, num tempo em que se demanda desses cursos que respondam à grande variedade de desafios sociais, tecnológicos, políticos e ecológicos, é de grande importância refletir sobre as condições atuais e o futuro desejável para os mesmos. O futuro da pós-graduação está ancorado em sua história específica em nosso país e em como se apresenta no presente momento. Nesse sentido, várias questões precisam ser respondidas: Qual o propósito e a natureza dos estudos na pós-graduação, em um momento de aceleradas mudanças? Que valor têm para as pessoas e a sociedade? Respostas devem ser buscadas junto a diversificados grupos de interesse e com diferentes referenciais.

Embora tenhamos nessa modalidade um reduto conservador que o enquadra em rígidos moldes, em nível das instituições não se tem claros os objetivos aos quais seus cursos atendem, ficando os propósitos da pós-graduação interpretados isoladamente por este ou aquele professor, pesquisador ou aluno, mantendose, no entanto, apenas propósitos gerais como intencionalidade institucional, no que se refere ao seu desenvolvimento.

Questionam-se, neste momento, portanto, aspectos relativos às finalidades, propostas, estruturas, currículos, formas de desempenho e tipos de qualidades socialmente relevantes esperadas dos cursos de mestrado e doutorado. Estes pontos vêm sendo postos em questão à luz de discussões sobre o papel social dessa modalidade educacional na atualidade, atualidade que se mostra com características novas diante da própria história construída nesses anos todos, desde o início da implementação da pós-graduação brasileira. Não há consenso sobre essas questões, quando se dá voz a profissionais diversificados e não apenas aos direta ou indiretamente comprometidos com o sistema vigente. Sistema este que, na verdade, não sofreu transformações desde sua origem, mas apenas ajustes ou adaptações que não alteraram o eixo da exclusão de vários setores interessados.

O debate sobre as questões acima apontadas está aberto. Em pesquisa que realizou, Peixoto (1995) identificou, quanto às concepções sobre as finalidades dos mestrados, três perspectivas: a primeira, é a de que o mestrado é uma iniciação à pesquisa; a segunda, é a de que o mestrado cumpre a função de dar formação acadêmica básica para docência, porém é o doutorado que inicia o discente na pesquisa; a terceira, que vê como finalidades do mestrado a formação de docentes para o ensino superior e a de assessores, afastada da preocupação de formar pesquisadores. Observa-se que nas instituições onde predomina a primeira concepção, os mestrados geralmente vêm sendo equivalentes a minidoutorados, e neles predomina o pensamento de que se perde qualidade ao colocar sua terminalidade em dois anos, como vêm impondo os órgãos avaliadores e de fomento.

Outros estudos identificam dois tipos de mestrado que se diferenciariam pelos seus objetivos. Um deles teria como objetivo estudos avançados em uma disciplina específica, sem preocupação com suas aplicações; outro visaria à aplicação e extensão de conhecimentos a finalidades profissionais ou vocacionais. Isto nos leva à questão dos mestrados profissionais. Conforme se encontra colocado em alguns documentos oficiais, a necessidade desta modalidade de estudos pósgraduados voltados para áreas de trabalho corresponde à própria evolução dos conhecimentos, seus impactos no mundo do trabalho, às mudanças dos mercados, o que induz a procura de recursos humanos que facilitem a transferência mais rápida dos conhecimentos gerados na universidade para a sociedade. Em todo o mundo procuram-se formas mais eficazes de estabelecer relações entre as universidades e setores governamentais, não-governamentais e sobretudo empresariais. São fatos sociais, não há como negá-los.

Mais uma vez aqui a polêmica se instala entre nós sobre questão internacionalmente superada, já que ainda se defende em círculos importantes nos setores da pós-graduação a formação estrita para a vida científica em termos de mestrados acadêmicos, propugnando-se a não implantação dos mestrados profissionalizantes. Ante a sua existência, volta-se o combate para sua não expansão ou depreciação.

Com pressões sociais evidentes, que correspondem a necessidades de setores do trabalho, sobretudo 
de novos setores como os da comunicação, parece que será necessária a construção de um novo tipo de compreensão quanto ao papel dos mestrados e doutorados, entendendo que conhecimento aprofundado pode conviver com problemas de trabalho mais ou menos imediatos, e que as diferenças entre modalidades formativas podem situar-se quanto à perspectiva temática e não necessariamente em uma desqualificação no nível formativo. A rigidez existente em certos círculos acadêmicos não tem permitido discussão realmente construtiva, em algumas áreas, para este tipo de demanda social: qual seu sentido, como e onde poderia desenvolver-se, qual seu papel. Essa modalidade de pós-graduação vem sendo implementada ao largo do eixo hegemônico que define os rumos de mestrados e doutorados e dos padrões definidos para sua avaliação. Esse tipo de curso vem encontrando abertura dentro dos órgãos normativos oficiais, mas sempre com a presença de ressalvas, como legitimação ante a perspectiva acadêmica dominante, pela promessa de "avaliação rigorosa", "avaliação no mesmo nível dos mestrados acadêmicos" etc., encontradas nos documentos oficiais. Revelam-se claramente a desconfiança na qualidade e a diferença de nível implícitas.

O desafio está na busca de um equilíbrio entre a preparação de professores para o ensino superior, a de pesquisadores e a de profissionais diversos que buscam seu aprofundamento teórico, cultural, científico ou tecnológico. Com flexibilização de tempos e de possibilidades nas trajetórias dentro dos cursos, este equilíbrio talvez possa ser atingido. A convivência de modalidades diferentes numa mesma instituição, que se qualifica também pela pesquisa e produção cultural de outras naturezas, pode dar sustentação a um ambiente adequado à não banalização de certas modalidades curriculares nesse nível formativo, e propiciar aos alunos convivência com formas diversificadas de produzir e utilizar conhecimentos. Mas, a exclusão de qualquer modalidade em favor de uma só pode resultar em empobrecimento de cursos e empobrecimento dos horizontes institucionais.

As diversas modalidades ou estruturas formativas na pós-graduação constituem questão socialmente im- portante hoje e necessita ser enfrentada dentro daquela consciência social ampliada que vimos colocando como necessária às transformações neste nível educacional. Mais um desafio: criar alternativas formativas diferenciadas em seus objetivos, mas com qualidade consistente à luz de padrões de referência diversificados e adequados a cada alternativa, e abrir brechas para que isto seja possível. Não se trata de rebaixar padrões de formação, mas de criar novos padrões também com boa qualidade.

Se esses programas devem se constituir em lugar de construção de aprendizagens, de exercício da investigação científica, de maturação quanto a teorias e tecnologias e de preparação para o exercício da docência em nível superior, novas relações educacionais internas a eles devem ser construídas. Isto requer alterações em papéis consagrados, criação de ambiências de aprendizagem para além das aulas e atividades estruturadas, criação de opções para estudo independente e possibilidade de desenvolvimento de programas exploratórios ou experimentais. Temos de enfrentar o conformismo ao modelo único, de finalidade única, e buscar formas organizacionais que tornem o espaço da pós-graduação espaço no qual de fato se exercite a exploração intelectual de problemas e temas, em tempo adequado a variados tipos de alunos, permitindo a eles a gestão desse tempo em limites razoáveis, propiciando o acesso a conhecimentos e à ampliação cultural, a grupos diferenciados e a profissionais que trabalham.

Todos os aspectos trazidos até aqui e mais o próprio desenvolvimento das áreas de conhecimento desafiam-nos, também, quanto à necessidade de rever organizações que fragmentam setores de conhecimento, buscando arranjos cooperativos para o desenvolvimento de estudos entre áreas e mesmo interinstitucionalmente. Criar condições de promover conhecimentos interconectados, facilitando acesso de professores e estudantes a outras áreas disciplinares, fora de sua especialidade específica; estabelecer intercomunicações entre áreas; facilitar caminhos para que se desenvolvam em métodos de análise interdisciplinares, promovendo seminários conjuntos, projetos de pesquisa 
interdisciplinares, colóquios; criando campos interdependentes de estudo ou outros mecanismos que alarguem as possibilidades de insights em conhecimentos que são, ao mesmo tempo, básicos em uma especialidade mas que necessitam de aportes de outros campos.

Ponto que vem sendo freqüentemente trazido à consideração para os anos vindouros é o do favorecimento de trabalhos de forma cooperativa, integrativa e menos individualista, propiciando espírito de grupo e trabalho em equipe. Espírito de colegiado, comunicações abertas. Isto também coloca questões à atual forma de desenvolvimento dos trabalhos nos mestrados e doutorados.

Se, na pós-graduação, se atuar com uma consciência social ampliada, atentos às condições para aprendizagens significativas e aos tempos humanos, em que estudo e trabalho são dimensões que não se excluem, os que nela atuam precisariam usar de suas competências para encontrar alternativas de transformações, nos mestrados e doutorados, de tal forma que sua contribuição à qualificação consistente dos novos e diversificados contingentes profissionais, cujas diferentes demandas começam a se colocar, seja de fato relevante.

Essas são questões das quais não se poderá fugir nos próximos anos.

\section{Flexibilidade e duração de cursos}

A partir das considerações que estamos tecendo sobre os desafios da pós-graduação, a questão do tempo de conclusão dos cursos de mestrado e doutorado precisa ser considerada em parâmetros bem diferentes dos que têm sido postos pelas agências governamentais e alguns setores acadêmicos. Com um olhar social mais sensível, tendo questões de eqüidade como referência, é necessário considerar as condições reais de quem hoje procura esse nível formativo, dos que potencialmente virão a procurá-los, e dos objetivos que em relação a ele começam a ter pessoas de diferentes segmentos sociais e setores do trabalho - objetivos que são socialmente construídos e não pré-determinados abstratamente. Não tem havido uma interlocução suficientemente ampliada dos acadêmicos com diversificados setores que começam a exigir interfaces com esse tipo de formação. Há um fato social ocorrendo: cada vez mais os estudantes deste nível têm que arcar com os custos deste ensino e dividir seu tempo entre trabalho e estudo. Este é o horizonte que se descortina no Brasil para os demandantes à pós-graduação. Assim, a questão de prazos rígidos para a conclusão dos cursos - e que afetam sua avaliação e os fomentos que podem receber - toma outra feição, pelo menos dentro de um pensar mais democrático de possibilidades de acesso ao saber. Os mestrandos e doutorandos nãobolsistas, que aos poucos se tornam a maioria dos alunos desses cursos, obviamente têm outras condições quanto à dedicação de tempo aos estudos, mas nem por isto são menos qualificados para aí estarem. Fechar possibilidades a este tipo de pós-graduando é criar mais um espaço de exclusão. É preciso considerar também que, trabalhando em geral em áreas afins aos seus estudos, os pós-graduandos emprestam a estes uma nova qualidade que advém da experiência no trabalho e do seu trato cotidiano com variados e concretos tipos de problemas. A questão do aluno-trabalhador e dos prazos de formação trazem um desafio e tanto para o modelo credencialista vigente e, diante das necessidades e condições reais dos estudantes nesse nível, esse modelo, com sua rigidez, parece colocar-se na contramão da história social. Em artigo recentemente publicado, Velloso e Velho (1997), analisando a pós-graduação, discutem a questão do tempo imposto rigidamente para a realização destes cursos, ponderando que a "fixação de prazos inadequados, segundo alguns autores, constitui não apenas fonte de frustração mas também de desperdício de tempo e dinheiro por parte dos estudantes e das instituições (Wilson, apud Stricker, 1994). Nos Estados Unidos da América, onde têm sido relativamente abundantes os estudos sobre os prazos de titulação, verificou-se que estes vêm aumentando desde os anos 60" (p.75).

Estudos em diversos países apontam na mesma direção. Os autores citados lembram que, em países cientificamente fortes, o mestrado tem um caráter re- 
sidual e por essa razão os estudos sobre esta questão referem-se mais ao doutorado. Citando vários trabalhos, mostram que o tempo gasto pelos estudantes matriculados neste nível passou de cerca de pouco mais de cinco anos para aproximadamente sete anos.

Também dentro da questão de acessibilidade, permanência e terminalidade nos cursos de mestrado e doutorado, é preciso lembrar que, diferentemente das propostas desenvolvidas em outros países, no Brasil as ofertas de atividades e disciplinas nesse nível mantêm o padrão semestral, sem ofertas diversificadas em épocas de verão ou inverno, períodos de férias escolares e outros, replicando disciplinas ou atividades já oferecidas no "semestre padrão" . Não são oferecidas também oportunidades de preenchimento de créditos em períodos alternativos, que podem ser estruturados no semestre mesmo, maximizando a utilização dos recursos institucionais e flexibilizando as trajetórias dos alunos. A inflexibilidade curricular cerceia oportunidades, especialmente para os alunos-trabalhadores; mais um grande desafio a superar.

Tudo isto tem a ver com o papel social que se pode esperar destes cursos e sobre o qual será necessário discutir, envolvendo-se segmentos diversificados, internos, inclusive os próprios alunos, e externos aos quadros do ensino superior. Propugnam-se como metas para a educação superior, no discurso, flexibilidade em estruturas e currículos, formação com flexibilidade cognitiva, mas a rigidez estrutural dos cursos e dos prazos, a homogeneização dos diferentes segmentos do alunado, com diferenciadas condições para dedicação aos estudos, bolsistas e não-bolsistas etc. mostram um sistema de mão única e via estreita, no qual oportunidades são restringidas e flexibilidade, inexistente. Este fato não permite aos estudantes experimentar essa qualidade concretamente e apreendê-la pelo exercício de escolhas. Este é um paradoxo educacional claro.

Superar essas condições é desafio. Reconhecer suas raízes pode ajudar nesse processo de transformação. Estas raízes estão vinculadas às origens de vocação elitista de nosso ensino superior, transferidas à pósgraduação, que é tomada como último reduto da qualidade, por certos grupos que confundem boa qualidade com grau de exclusão. A manutenção desta postura vem desfavorecendo variados contingentes sociais quanto às possibilidades de aprofundamento de sua formação. Os setores envolvidos com mestrados e doutorados precisam ampliar suas perspectivas sociais, sem perder a ciência como referencial. Devem reconhecer, no entanto, que, como processos educativos, com objetivos também diferenciados, mestrados e doutorados são meios de fazer ascender a padrões culturais diferentes segmentos sociais, à altura das conquistas humanas em conhecimentos. Passa também por este nível formativo a socialização dos conhecimentos acumulados pelo esforço e contribuição de todos os cidadãos que, em última instância, fornecem o dinheiro necessário ao financiamento de cursos e pesquisas, por meio de impostos. Portanto, o papel social desse segmento educativo é também do interesse público.

Sob o ângulo que vimos desenvolvendo, o desafio está em não comprometer a formação desses novos contingentes que estão demandando este nível de cursos, todos com direito a uma boa formação, com a contrapartida de sua própria responsabilidade em relação a essa formação. As dificuldades ante mudanças forçam a manutenção da visão dominante, mas estamos alijando pessoas e profissionais que teriam nesses cursos oportunidade de desenvolvimento pessoal, profissional, social e científico de todo relevantes para os desafios dos anos vindouros. Estamos, em nível dos mestrados e doutorados, de certa forma, criando diques contra a ampliação social de potencialidades humanas. Democratizar acesso, flexibilizar currículos, formatos e tempos, construir diferentes trajetórias possíveis nesses cursos, com formas de terminalidade diversificadas, não quer dizer "perda de qualidade" . A boa qualidade das aprendizagens não passa certamente por formatos fechados e padrões pré-estabelecidos, quando se trata de formação de pessoas e do desenvolvimento e ampliação de suas potencialidades. Tem faltado criatividade e ousadia na busca de rotas diversificadas e alternativas para dar respostas às demandas que são feitas nesse nível educacional, demandas que aumentarão em muito. O desafio será atender 
a todo um novo contingente que começa a procurar esse nível educacional, com heterogêneas necessidades, suplantando a idéia de que boa qualidade se faz criando reservas de domínio em áreas de conhecimento.

\section{Conhecimento e poder}

Voltemos agora à questão já levantada sobre concentração de "conhecimento" em poucos círculos. Este aspecto é importante, pois está na base de concepções sobre o papel da pós-graduação e dos desafios que vimos colocando.

O grande dilema a ser enfrentado por mestrados e doutorados é o de abrir-se a novas perspectivas, modalidades curriculares e tipos de discentes, ou manterse como área reservada a poucos, com critérios de seletividade definidos segundo um único padrão. Na base deste desafio está a questão de uma perspectiva relativa ao princípio de equiidade, como valor social e ético, que se apresenta como fundamental ao futuro das sociedades humanas e até como condição de sustentação de um processo de sobrevivência civilizada.

Estudos e ensaios que discutem a relação entre conhecimento e poder têm sido produzidos com certa intensidade nas duas últimas décadas. Assinalam que uma das transformações que vêm se produzindo nas sociedades avançadas aparece nos determinantes de desigualdades sociais. Entre estes surge o conhecimento como princípio diferenciador de pessoas e grupos humanos. Deter certos conhecimentos é poder obter vantagens e facilidades no movente mundo atual. Na expressão de Stehr (2000) a "emancipação de amplos segmentos da população de uma condição de vulnerabilidade e subordinação econômica - que não se realiza na mesma extensão e em velocidade semelhante em todos os países industrializados - proporciona as bases materiais para novas formas de desigualdade" (p.102).

À medida que as sociedades industriais vão sendo impregnadas por uma sociedade do conhecimento e por ela substituída, considerar as novas formas de produção de desigualdades é necessário. Uma delas é a posse de conhecimentos necessários para formas de agir, conhecimentos que estão na base de ações que podem trazer melhores condições de acesso a bens sociais valorizados. Contemporaneamente e nos anos vindouros, cada vez mais o acesso a e o domínio de conhecimentos relevantes socialmente associam-se a domínio de linguagens, ciências, tecnologias, domínio de estruturas que regulam direitos e relações de diferentes naturezas. Nessa perspectiva, não só a educação básica e superior das pessoas entram em jogo, mas também a pós-graduação, na medida mesma da sofisticação das sociedades, dos tipos de conhecimento e suas formas de produção, e dos recursos necessários à sobrevivência humana.

Embora a concepção, em geral, de conhecimento que têm os autores que tratam dessa questão seja uma concepção ampliada, pois não diz respeito ao conhecimento científico ou instrumental estrito, referindo-se a um conjunto mais amplo de meios de construção de habilidades e competências sociais, que se revelam em formas novas de agir e mediações que abrem perspectivas diferenciadas de sucesso na vida cotidiana, na base destas possibilidades está o saber buscar e interpretar informações e tipos de conhecimento que, em última instância, derivam, direta ou indiretamente, de avanços científicos e culturais em vários setores. $\mathrm{O}$ domínio destes saberes constitui-se em poder, poder que pode ser exercido de diferentes maneiras.

De acordo com Stehr (2000), a

\begin{abstract}
[...] condição que possibilita obter bases de ação mais amplas e mais numerosas é o conhecimento, ou seja, um conjunto de competências sociais de acesso mais geral, cujo impacto sobre as estruturas sociais de desigualdade acelera as oportunidades dos atores de reformular as construções sociais (p.108). [Então, no compasso em que] o conhecimento vai tomando o lugar da propriedade e do trabalho como mecanismo constitutivo da desigualdade, a relação dos indivíduos e dos grupos com o conhecimento passa a ter uma importância fundamental para os padrões de desigualdade social nas sociedades contemporâneas (p. 109).
\end{abstract}

Sob esta ótica, para quem tem no seu horizonte idéias como eqüidade social, oportunidades distribuídas, relações cooperativas, o sistema de pós-gradua- 
ção de hoje deverá ser merecedor de profundas alterações na direção de abertura de oportunidades, de acesso ao conhecimento que aí pode ser oferecido a diferenciados segmentos sociais. Este nível formativo começa a ser requisitado a oferecer respostas, a curto prazo, a pressões que não tardarão a mostrar-se com força, entre elas a das condições de sobrevivência humana e da qualidade de vida e das relações sociais. Mas, não só. Na perspectiva de quem defende a construção de uma sociedade mais igualitária, a forma como hoje vem sendo desenvolvida a pós-graduação deve sofrer algumas mudanças radicais. As concepções dominantes hoje estão entrando em crise. Os contrastes entre conhecimento científico, conhecimento ético e eqüidade social deverão ser merecedores de uma ampla e pública discussão, se os que atuam neste nível de ensino desejarem ser partícipes das transformações que despontam no horizonte desses cursos. Esta participação será essencial à medida que se reconhecer que mestrados e doutorados devem estar envolvidos com uma ética da vida que implique a superação de processos que alimentam a excessiva desigualdade entre pessoas e grupos. Isto conduz à necessidade de rearticulação dos domínios do conhecimento com a responsabilidade social. Um novo tipo de consciência humano-social-científica será requerido para encaminhar estas transformações.

BERNARDETE ANGELINA GATTI é docente do Programa de Pós-Graduação em Psicologia da Educação da PUC/SP e coordenadora do Departamento de Pesquisas Educacionais da Fundação Carlos Chagas. Publicou recentemente: A new model for teacher training, Texts from Brazil n ${ }^{\circ}$ 7: Education for human and social development in Brazil, (Ministry of Foreign Relations, 2000, p.3943); Ensino superior e avaliação institucional, Revista Brasileira de Estudos Pedagógicos (Brasília: INEP/MEC, n 194, vol. 80, jan.-abr. 1999, publicado em jan. 2001, p. 148-155); Implicações e perspectivas da pesquisa educacional no Brasil contemporâneo, Cadernos de Pesquisa (Fundação Carlos Chagas \& Autores Associados, $\mathrm{n}^{\circ}$ 113, jul. 2001, p.65-81). Pesquisa atual: “Aspectos psicossocioeducacionais em programas de formação continuada e à distância de professores”. E-mail: gatti@fcc.org.br

\section{Referências Bibliográficas}

DURHAM, Eunice R., (1996). A pós-graduação no Brasil: problemas e perspectivas. NUPES/USP, Documento de Trabalho $8,21 \mathrm{p}$.

GUADILLA, Carmen García, (1997). Universidade latino-americana: da casela vazia ao cenário socialmente sustentável. $\mathrm{Ca}$ dernos de Pesquisa, Fundação Carlos Chagas \& Cortez Editora, $n^{\circ} 101$, p. 82-112, jul.

LOUREIRO, Maria Rita, DURAND, José Carlos. (1995). A pósgraduação profissional em Administração comparada à pós-graduação acadêmica. Cadernos de Pesquisa, Fundação Carlos Chagas \& Cortez Editora, n ${ }^{\circ}$ 94, p.5-14, ago.

PEIXOTO, Maria do Carmo. (1995). Formação do pesquisador na pós-graduação: análise da estrutura organizacional em duas áreas do conhecimento. Conselho de Reitores das Universidades Brasileiras. Educação Brasileira, vol. 17, n 34, p.125-144, jan.-jun.

STEHR, Nico. (2000). Da desigualdade de classe à desigualdade do conhecimento. Revista Brasileira de Ciências Sociais, vol.15, $\mathrm{n}^{\circ} 42, \mathrm{p} .101-112$.

STRICKER, L.J. (1994). Institutional factors in time for the doctorate. Research in Higter Education, v. 35, n 5, p. 569-587.

VELLOSO, Jacques, VELHO, Lea. (1997). Política de bolsas, progressão e titulação nos mestrados e doutorados Cadernos de Pesquisa, n 101, Fundação Carlos Chagas \& Autores Associados, p. 50-81. 
mais ligados aos movimentos sociais, que recorrem dominantemente à teoria social e à antropologia e os autores mais ligados a questões pedagógicas, que tendem a se apoiar na teorização de currículo, na teoria crítica, nos estudos culturais e no pensamento pósmoderno e pós-estrutural.

\section{Recent scientific production on} curriculum and multiculturalism in Brazil (1995-2000): advances, challenges and tensions

This article presents an analysis of recent Brazilian scientific production on curriculum and multiculturalism. It examines articles published between 1995 and 2000 in the following journals: Cadernos de Pesquisa, Revista Brasileira de Educação, Educação \& Realidade, Educação \& Sociedade e Educação em Revista. It also focuses on papers presented at the Annual Meetings of ANPEd during the same period. The study aims at identifying the main themes and arguments, the most significant theoretical influences, the methodological procedures employed, the contributions and the gaps. The tensions and challenges observed in the articles are also discussed. The paper insists on the importance of a dialogue between those authors more closely associated with social movements who are chiefly influenced by social theory and anthropology and those authors more closely associated with curriculum and pedagogy who are influenced by critical theory, cultural studies, post-modernism and post-structuralism.

Iria Brzezinski e Elsa Garrido

Análise dos trabalhos do GT Formação de Professores: o que revelam as pesquisas do período 1992-1998

O texto analisa setenta trabalhos apresentados no GT Formação de Profes- sores da ANPEd, no período19921998. As pesquisas foram organizadas segundo cinco descritores: formação inicial de professores, formação continuada, práticas pedagógicas, profissionalização docente e revisão da literatura sobre formação de professores. $\mathrm{O}$ estudo procura oferecer uma visão compreensiva sobre as questões, os referenciais teóricos e os avanços do conhecimento na área, explorando relações, explicitando divergências e delineando tendências de pesquisa. $\mathrm{O}$ conjunto dos trabalhos traz contribuições para fundamentar e subsidiar propostas e políticas de formação e de desenvolvimento profissional docente.

\section{Papers presented in the Working Group on Teacher Formation - what the research in the period 1992-1998 reveals}

This texts sets out to analyse seventy papers presented in the ANPEd Working Group on Teacher Formation during the period 1992-1998. The research was organised employing five categories: initial teacher formation, continued formation, pedagogical practices, teacher professionalisation and literature review on teacher formation. The study seeks to offer a comprehensive vision with regard to theoretical frameworks and recent advances in the area, exploring relations, expressing divergences and outlining research tendencies. The set of papers offers contributions to substantiate proposals and policies for teacher formation and professional development.

\section{Maria Rita Neto Sales Oliveira}

Do mito da tecnologia ao paradigma tecnológico; a mediação tecnológica nas práticas didático-pedagógicas O objetivo principal do texto é apresentar uma visão crítica da tecnologia no âmbito da educação e do ensino.
Aborda três hipóteses sobre a matéria: tecnologia educacional revisitada, modelo da competência e mito da tecnologia, evidenciando seus problemas, reducionismos e limites. Em sequiência, discute as características do novo paradigma tecnológico, e alguns aspectos do Livro verde do Ministério da Ciência e Tecnologia do país. Como conclusão, levanta algumas implicações da necessária superação dos problemas apontados, para o entendimento e tratamento crítico das tecnologias nas práticas didático-pedagógicas.

From the myth of technology to the technological paradigm: technological mediation in pedagogical practices The main objective of the text is to present a critical perspective on technology in education and teaching. Three hypotheses are discussed: educational technology revisited, the competence model and the myth of technology. The text also discusses the characteristics of the new technological paradigm and some aspects of The green book published by the brazilian Ministry of Science and Technology. In conclusion, the article points to some of the implications linked to a critical understanding and treatment of technology in teaching and educational practice.

Bernardete Angelina Gatti

Reflexão sobre os desafios da pósgraduação: novas perspectivas sociais, conhecimento e poder $\mathrm{O}$ artigo salienta as diferenças entre o momento histórico em que os programas de mestrado e doutorado foram criados e o momento atual. Discute-se o papel social desses cursos na dicotomia conhecimento $x$ poder e o dilema a ser enfrentado por mestrados e doutorados que vêm sendo instados, pela sociedade, a abrir-se a novas modali- 
dades curriculares e tipos de discentes. Contrapõe-se a isso o manter-se como área reservada a poucos. A partir da consideração que as desigualdades sociais em seus determinantes incluem as desigualdades de acesso e incorporação de conhecimentos em todos os níveis, coloca-se como desafios ao modelo atual o atendimento a diferentes tipos de clientela, com diferentes interesses. Coloca-se a necessidade de uma reavaliação do papel desses cursos, seu valor social e suas estruturas numa sociedade em mutação.

\section{Reflections on the challenges of} postgraduate studies: new social perspectives, knowledge and power

This article emphasises the differences between the historical moment in which postgraduate programmes (master and $P h D)$ were created and the present one. It discusses the social role of these courses in the dichotomy knowledge $x$ power and the dilemma faced by these programmes when urged by society to include innovative curricular modalities and to accept new student profiles in opposition to maintaining themselves as a field reserved for the chosen few. Based on considerations that the determinants of social inequalities include different opportunities of access to and appropriation of knowledge, the article poses a challenge to the present model of postgraduate studies: to revise its social role, values and curriculum in order to attend a different type of public, with diverse interests.

Gilberto Dupas

Ética e poder na sociedade da informação; revendo o mito do progresso Durante o século XX, o capitalismo global apossou-se por completo dos destinos da tecnologia, libertando-a de amarras metafísicas e orientando-a única e exclusivamente para a criação de valor econômico. Transformados em fator fundamental na disputa dos mercados e na acumulação capitalista global, os vetores tecnológicos autonomizaram-se definitivamente de considerações de natureza ética, social ou de políticas públicas. As conseqüências foram, dentre outras, o aumento da concentração de renda e da exclusão social, o perigo de destruição do habitat humano por contaminação e a manipulação genética, ameaçando o patrimônio comum da humanidade.É preciso pois buscar condições para que nova hegemonia mundial, que inclua mas não se constranja ao capital, possa construir um mundo melhor, utilizando-se dos avanços da ciência em benefício da grande maioria de seus cidadãos.

Ethics and power in the information society: reviewing the myth of progress

During the $20^{\text {th }}$ Century, global capitalism took complete control of the destiny of technology, freeing it from its metaphysical chains and directing it exclusively to the creation of economic gain. Transformed into a fundamental component in the dispute for markets and in global capitalist accumulation, the technological vectors freed themselves from all considerations of an ethical, social or public policy nature. The results of this process, amongst others, were the increase in the concentration of income and of social exclusion, the danger of the destruction of the human habitat from contamination and genetic manipulation, which threaten the common patrimony of humanity. It is necessary to create a new world hegemony, including but not limited to capital, as the premise for the construction of a better world in which scientific advances are used to the benefit of the great majority of citizens. 